\title{
Chemistry of gem-Dihalocyclopropanes. XVIII. Reactions of gem-Dibromocyclopropylmethyl Sulfides with Methyllithium
}

\author{
JACEK ARCT and LARS SKATTEBØL
}

\author{
Department of Chemistry, University of Oslo, P.O. Box 1033, Blindern, Oslo 3, Norway
}

gem-Dibromocyclopropylmethyl sulfides 3 were prepared in good yields from 1,1-dibromo-2-iodomethylcyclopropane 4 and the appropriate sodium thiolate. Compounds 3 reacted with methyllithium to give products that were separated into low and high boiling fractions. The former contained the allenes 5, the 3-thiabicyclo[3.1.0]hexane derivatives 6,7 and 8 , and the methylated monobromides 9. The nonvolatile parts were shown to consist of stereoisomers of the bicyclopropylidenes 10 . The product composition varied with the reaction temperature. The yields of 10 were highest at $-78^{\circ} \mathrm{C}$ reaching $85 \%$ in the case of $10 a$. The amounts of bicyclic sulfides increased with rising temperature. The mechanism of formation of the products is discussed.

The cyclopropylidene intermediate generated from gem-dibromocyclopropanes and alkyllithium can undergo a variety of reactions. ${ }^{1}$ Insertion into $\mathrm{C}-\mathrm{H}$ bonds is commonly observed and can also be useful synthetically. Early work by Moore et al. ${ }^{2 \mathrm{a}}$ indicated that intermolecular insertion into $\mathrm{C}-\mathrm{H}$ bonds adjacent to an oxygen function was favoured, and Baird ${ }^{3}$ later showed that high yields of the intramolecular insertion products 2 were obtained from the ethers 1 (Scheme 1). Several examples of similar intramolecular insertion reactions have since been
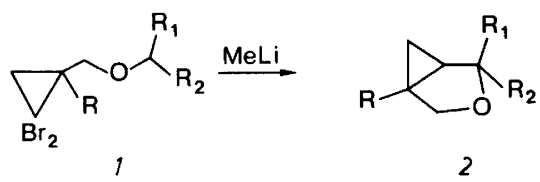

Scheme 1. reported involving ethers, ${ }^{4}$ alcohols ${ }^{5}$ and amines. ${ }^{6}$ In the present work we want to report that among other reactions insertion also takes place with sulfides of the general structure 3 .

After this work was completed, Baird reported ${ }^{7}$ a similar study. With one exception, different sulfides have been used in the two studies and more important, our results differ sufficiently to justify publication.

The sulfides were conveniently obtained in high yields by thiolate anion displacement of iodide from 1,1-dibromo-2-iodomethylcyclopropane (4), which is readily available from the corresponding chloride. $^{8}$ The latter also undergoes displacement with thiolate anions, but as expected, at a considerably slower rate. The preparation of these compounds by addition of dibromocarbene to allyl sulfides, has not been successful, ${ }^{9}$ which may explain why very few examples of this potentially interesting class of compounds are described in the literature.

Solutions of the sulfides in ether were treated with methyllithium at two temperatures, -78 and $0{ }^{\circ} \mathrm{C}$. The products consisted invariably of a volatile fraction which was separated by distillation, and a residue which could not be distilled without partial decomposition, but was purified by column chromatography. Most of the compounds constituting the volatile part were isolated by preparative gas liquid chromatography (GLC) some compounds remained unindentified, but more than $85 \%$ of the total product was accounted for in each case. The results are depicted in Scheme 2 and Table 1.

The products from all reactions, except that from $3 a$, consisted essentially of four compounds of the structures $5-10$. The amount of volatile material, 
Table 1. Products from reactions of the sulfides 3 with methyllithium.

\begin{tabular}{lll}
\hline Starting material & Reaction temp. $\left({ }^{\circ} \mathrm{C}\right)$ & Products $\left(\%\right.$ yields) $^{a}$ \\
\hline $3 a$ & -78 & $5 a(4), 10 a(86)$ \\
& 0 & $5 a(67), 10 a(20)$ \\
$3 b$ & -78 & $5 b(6), 6(14), 9 b(9), 10 b(59)$ \\
& 0 & $5 b(21), 6(17), 96(7), 10 b(40)$ \\
$c$ & -78 & $5 c(2), 7(34), 9 c(6), 10 c(48)$ \\
& 0 & $5 c(16), 7(21), 9 c(7), 10 c(42)$ \\
$3 d$ & -78 & $5 d(2), 8(15), 9 d(5), 10 d(67)$ \\
& 0 & $5 d(19), 8(38), 10 d(38)$ \\
\hline
\end{tabular}

${ }^{a}$ The values for compounds 5-9 are based on GLC analysis of distilled material while the values for compounds 10 are based on material isolated by column chromatography.
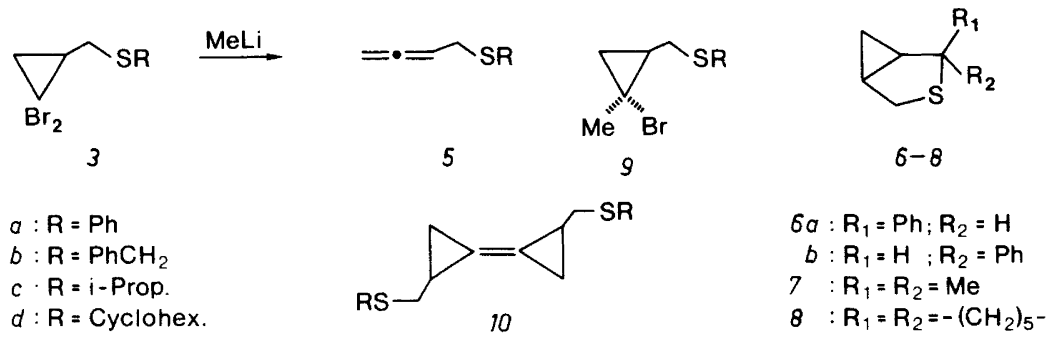

Scheme 2.

$5-9$, increased at higher temperature. The structural assignments are based on spectral data, particularly the NMR spectra. The allenes 5 were formed in all reactions, and the IR spectra exhibited absorption at about 1960 and $855 \mathrm{~cm}^{-1}$, characteristic of a terminal allenic linkage.

The bicyclic sulfide 6 appeared homogeneous by GLC, but the ${ }^{1} \mathrm{H}$ NMR spectrum revealed the presence of two stereoisomers in a ratio of approximately $5: 2$. The benzylic proton of the major isomer appears as a doublet, $J=3 \mathrm{~Hz}$, at $\delta 4.68$, while in the minor isomer the same proton resonates as a singlet at $\delta 4.31$. Unfortunately, there are no conformational studies of the 3-thiabicyclo[3.1.0]hexane ring system, but the 3-oxa analogue has been investigated using microwave spectroscopy. ${ }^{10}$ It has a boat conformation with a torsional angle of the $\mathrm{C}-2$ oxygen bond of $42^{\circ}$. We assume that 6 will have a similar geometry but with a smaller torsional angle to sulfur. According to this model the benzylic proton and the vicinal cyclopropyl proton will be nearly eclipsed in a cis configuration, suggesting that the major component of 6 is the endo isomer, i.e. ${ }^{6 a}$ Support for the assignment is provided by comparison with the ${ }^{1} \mathrm{H}$ NMR spectrum of 3azabicyclo[3.1.0] hexane, ${ }^{11}$ which shows a vicinal coupling of $3 \mathrm{~Hz}$ for the exo and negligible coupling for the endo proton. In the case of $9 c$, GLC analysis revealed the presence of two isomers in a ratio of $\sim 1: 1$. It is not apparent from the ${ }^{1} \mathrm{H}$ NMR spectra, but we assume that all compounds 9 are mixtures of stereoisomers. The methyl group adjacent to bromine appears as a singlet at $\delta 1.75 \pm 0.04$ in all three derivatives, in good agreement with data available for similar compounds. ${ }^{12}$

The bicyclopropylidenes 10 constitute the major part of the nonvolatile products. The NMR spectra are in accordance with the assigned bicyclopropylidene structures, but we could not on this basis ascertain which isomer was actually formed. Fortunately, the dimer $10 a$ was obtained in high yield as a crystalline compound, m.p. $106-107^{\circ} \mathrm{C}$, which appeared homogeneous. An X-ray crystallographic determination, ${ }^{13}$ established the structure as trans-2,3'bis(phenylthiomethyl)1, $1^{\prime}$-bicyclopropylidene $(10 a)$ with a short, 1.303(2) § double bond, very similar to that determined recently for another bicyclopropylidene derivative. ${ }^{14}$ For symmetry reasons this bond should be inactive in infrared, but active in the Raman spectrum. Surprisingly, the $\mathrm{C}=\mathrm{C}$ stretching band was absent or very weak in the Raman spectra of all the bicyclopropylidene derivatives 
Table $2 .{ }^{13} \mathrm{C}$ NMR chemical shifts for bicyclopropylidene derivatives 10 .

\begin{tabular}{lllll}
\hline Compound & \multicolumn{4}{c}{ Chemical shifts $(\delta$ ppm $)$} \\
& $\mathrm{C}-1$ & $\mathrm{C}-2$ & $\mathrm{C}-3$ & $\mathrm{C}-4$ \\
\hline $10 a$ & 115.7 & 15.7 & 10.9 & 37.9 \\
$10 b$ & 115.5 & 15.7 & 10.5 & 34.6 \\
$10 \mathrm{c}$ & 115.4 & 15.9 & 10.3 & 34.0 \\
$10 d$ & 115.5 & 16.1 & 10.5 & 33.5 \\
\hline
\end{tabular}

investigated so far, ${ }^{14,15}$ and $10 a$ is no exception in this respect. On the other hand, the Raman spectra of both 2,2,3'3'-tetrachloro-2',2',3,3-tetramethyl and

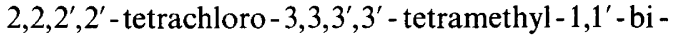
cyclopropylidene exhibit bands of medium intensity at 1851 and $1825 \mathrm{~cm}^{-1}$, respectively, which are assigned to the double bond. ${ }^{16}$ The intensity of this band appears to be strongly dependent on the substituents. The ${ }^{13} \mathrm{C}$ chemical shifts in the NMR for the ring carbons of the dimers 10 are recorded in Table 2. The close similarity of the data lead us to assign an $E$ relationship of the substituents for compounds $10 b-10 d$ as well, but we do not know whether they are trans, cis or indeed mixtures.

It is established that the first step in reactions of gem-dibromocyclopropanes with methyllithium involves an exchange of bromine for lithium with formation of the corresponding $\alpha$-bromocyclopropyllithium derivative, which for the present reactions will have the general structure 11 . Its formation is normally very fast even at $-78^{\circ} \mathrm{C}$ and it may react further in several ways. Elimination of lithium bromide leads to an intermediate 12 with chemical properties expected of a carbene. For simplicity we prefer to draw this intermediate as a cyclopropylidene bearing in mind, however, that it is most probably in some way both complexed with lithium bromide and solvated. ${ }^{17}$ The rate of lithium bromide elimination from intermediates like 11 is strongly affected by the substituents on the cyclopropane ring. Indeed, with oxygen- or nitrogencontaining substituents that complex with lithium, the formation of 12 becomes slow even at $0^{\circ} \mathrm{C}$ and products derive also from the organolithium derivative. Sulfur is also able to interact with lithium and products derived from 11 were expected at low temperature, at least.

The allenes 5 are formed by ring opening of the cyclopropylidene 12 , while intramolecular insertion leads to the bicyclic compounds $6-8$. With alkyl-

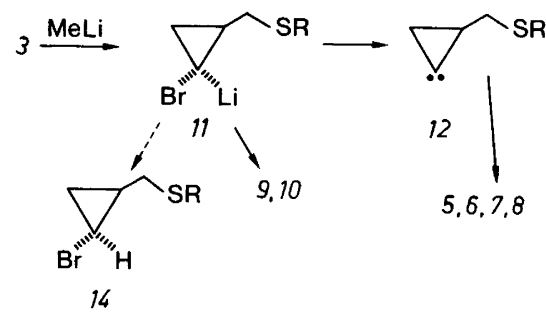

Scheme 3.

substituted cyclopropylidenes the ratio of ring opening to insertion is strongly influenced by the number of substituents ${ }^{18}$ as well as their bulk $;{ }^{19,20}$ insertion into the 3,4-related $\mathrm{CH}$ bond (1,3 insertion) forming bicyclobutanes has been observed, and normally as the predominant reaction with tetrasubstituted derivatives. ${ }^{18}$ On the other hand, the cyclopropylidenes 12 as well as the oxygen ${ }^{3}$ and nitrogen ${ }^{6}$ analogues undergo insertion exclusively into the 5,6-related $\mathrm{CH}$ bond (1,5 insertion). At $0{ }^{\circ} \mathrm{C}$ comparable amounts of allenes and insertion products are formed from $3 b-3 d$; the ratio is larger than that found for ethers and amines, but at $-78^{\circ} \mathrm{C}$ almost negligible amounts of allenic products are formed.

The heteroatom clearly influences the insertion reaction in two ways: (i) the rate is enhanced at the adjacent $\mathrm{CH}$ bond and (ii) specifically at the 5,6related bond. How the heteroatom exerts this effect is not clear. It has been suggested ${ }^{21}$ that during insertion a positive charge develops at the carbon from which the hydrogen migrates, and oxygen, nitrogen and sulfur are capable of stabilizing this charge leading to rate enchancement. A kinetic study, ${ }^{20}$ however, on intramolecular cyclopropylidene insertion into benzylic methylene groups indicates that only little charge develops in the transition state. The charge stabilizing effect may be important, but it does not explain the regioselective 1,5 insertion. This is particularly demonstrated by the results from the reaction of $3 a$; the allene $5 a$ was obtained as the only volatile product, although 1,3 insertion is available as a reaction path. Conformational effects certainly play an important role in insertion reactions. ${ }^{4,22}$ Some kind of interaction between the vacant $p$-orbital of the cyclopropylidene and a filled orbital of the heteroatom could cause the molecule to attain a conformation ideal for 1,5 insertion. The bicyclic components may actually not result from insertion, but rather from a Stevens 


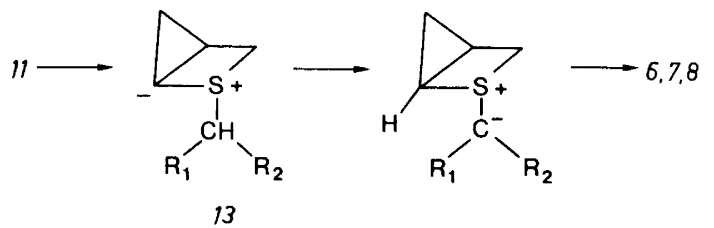

Scheme 4.

type rearrangement ${ }^{23}$ of an intermediate zwitterion (ylid) 13 as outlined in Scheme 4. This reaction path would accommodate the regioselectivity and evidence in support of such a mechanism has been obtained from reactions of electrophilic carbenes with sulfides, ${ }^{9,24}$ ethers ${ }^{25}$ and amines. ${ }^{26}$

Most reactions produced low yields of a third volatile compound, viz. the monobromides 9 . They are products derived from the $\alpha$-bromocyclopropyllithium intermediate 11 and methyl bromide, a well documented reaction. ${ }^{12,27}$ Some additional volatile products were present in the reaction mixtures and we cannot therefore exclude that the monobromides 14 were formed in small amounts, but we have no evidence for that.

The most remarkable result of the present study is the formation of the bicyclopropylidenes 10 in relatively high yields. These compounds are formally dimers of the corresponding carbene and they were actually encountered in early work on the reactions of gem-dibromocyclopropanes with methyllithium..$^{2 b}$ Only few examples of the dimers have since been reported as products from similar reactions; $;{ }^{14,28,29}$ with one exception, ${ }^{29}$ yields were usually low but highest at low reaction temperature and in the presence of lithium iodide. ${ }^{28}$ All evidence point to 11 as the precursor of the dimers 10 . They may form either from reaction of two molecules of the intermediate or by its reaction with a molecule of starting material. Apparently, the intramolecular coordination of lithium in 11 is beneficial for dimerization, but intermolecular complexation may be equally important.

In spite of the complexity of the products compiled in Table 1, the present reaction may be of use synthetically for the preparation of compounds incorporating the 3-thiabicyclo[3.1.0]hexane ring system and derivatives of bicyclopropylidene. No real effort was spent optimizing the yields of 6,7 and 8 , but reaction at $-78^{\circ} \mathrm{C}$ of one fourth the usual concentration of $3 c$ gave 7 and $10 c$ in 51 and $31 \%$ yields, respectively, and only small amounts of $5 c$ and $9 c$.
The results of the present work agree well with those reported by Baird ${ }^{7}$ with regard to formation of the allenes and bicyclic compounds; only the reaction of $3 c$ was actually carried out in both studies. The discrepancies arise in connection with the methylated monobromides 9 and the dimers 10 , which were not reported by Baird; on the other hand, he reported the formation of 14 . Our reactions were carried out at similar concentrations to those described by Baird, but at lower temperatures; moreover, the methyllithium used in the two studies came from different suppliers and the content of lithium bromide will probably affect the reaction as well. More data is required in order to clarify the influence of these factors on the product composition.

\section{EXPERIMENTAL}

NMR spectra were recorded on Varian EM 360A and Jeol JNM FX60 spectrometers. The mass spectra were obtained on an MM 7070 GLC/MS instrument. Elemental analyses were performed by I. Beetz, West Germany.

1,1-Dibromo-2-iodomethylcyclopropane (4). A solution of $23.6 \mathrm{~g}(0.1 \mathrm{~mol})$ of 2-chloromethyl-1,1dibromocyclopropane ${ }^{8}$ and $30.6 \mathrm{~g}(0.2 \mathrm{~mol})$ of $\mathrm{NaI}$ in $180 \mathrm{ml}$ of acetone was heated under reflux for $30 \mathrm{~h}$. The acetone was evaporated and water was added to the residue. The product was extracted with $\mathrm{CH}_{2} \mathrm{Cl}_{2}$, dried $\left(\mathrm{MgSO}_{4}\right)$ and solvent evaporated. Distillation afforded $29.7 \mathrm{~g}(91 \%)$ of 4 , b.p. $62-63{ }^{\circ} \mathrm{C}(0.4 \mathrm{mmHg})$; Anal. $\mathrm{C}_{4} \mathrm{H}_{5} \mathrm{Br}_{2} \mathrm{I}: \mathrm{C}, \mathrm{H}$. ${ }^{1} \mathrm{H}$ NMR $\left(\mathrm{CCl}_{4}\right): \delta 1.35(1 \mathrm{H}, \mathrm{m}) 2.03(2 \mathrm{H}, \mathrm{m}) 3.28$ $(2 \mathrm{H}, \mathrm{m}) ;{ }^{13} \mathrm{C} \mathrm{NMR}\left(\mathrm{CCl}_{4}\right): \delta 4.3\left(\mathrm{CH}_{2}-\mathrm{I}\right) 29.4$ $\left(\mathrm{CBr}_{2}\right) 31.0$ (cyclopropyl $\mathrm{CH}_{2}$ ) 32.5 (cyclopropyl $\mathrm{CH})$.

Preparation of sulfides (3). General procedure. To a solution of the sodium salt of the appropriate thiol $(20 \mathrm{mmol})$ in $30 \mathrm{ml}$ of methanol was added the iodide (4) $(20 \mathrm{mmol})$. The mixture was heated with reflux for $2-3 \mathrm{~h}$. $\mathrm{MeOH}$ was distilled off, and a mixture of water $(10 \mathrm{ml})$ and ether $(50 \mathrm{ml})$ was added to the residue. The ether layer was separated, washed successively with $10 \%$ aq. $\mathrm{NaOH}$ and water and dried $\left(\mathrm{MgSO}_{4}\right)$. The product was isolated by distillation.

2,2-Dibromo-1-phenylthiomethylcyclopropane (3a), b.p. $110-112^{\circ} \mathrm{C}(0.01 \mathrm{mmHg})$. Anal. $\mathrm{C}_{10} \mathrm{H}_{10} \mathrm{Br}_{2} \mathrm{~S}$ : C.H. ${ }^{1} \mathrm{H} \mathrm{NMR}\left(\mathrm{CCl}_{4}\right): \delta 1.28(1 \mathrm{H}, \mathrm{m}) 1.4-2.0(2 \mathrm{H}$, m) $3.03(2 \mathrm{H}, \mathrm{dq}, J=6$ and $13 \mathrm{~Hz}) 7.26(5 \mathrm{H}, \mathrm{m})$.

1-Benzylthiomethyl-2,2-dibromocyclopropane (3b), b.p. $116-118^{\circ} \mathrm{C}(0.01 \mathrm{mmHg})$. Anal. $\mathrm{C}_{11} \mathrm{H}_{12} \mathrm{Br}_{2} \mathrm{~S}$ : C,H. ${ }^{1} \mathrm{H}$ NMR $\left(\mathrm{CCl}_{4}\right): \delta 1.22(1 \mathrm{H}, \mathrm{m}) 1.3-2.0$ $(2 \mathrm{H}, \mathrm{m}) 2.53(2 \mathrm{H}, \mathrm{m}) 3.72(2 \mathrm{H}, \mathrm{s}) 7.18(5 \mathrm{H}, \mathrm{s})$. 
2,2 - Dibromo - 1 - isopropylthiomethylcyclopropane (3c), b.p. $61-62^{\circ} \mathrm{C}(0.01 \mathrm{mmHg})$. Anal. $\mathrm{C}_{7} \mathrm{H}_{12} \mathrm{Br}_{2} \mathrm{~S}$ : C,H. ${ }^{1} \mathrm{H}$ NMR $\left(\mathrm{CCl}_{4}\right): \delta 1.3(6 \mathrm{H}, \mathrm{d}, J=6 \mathrm{~Hz})$ $1.0-3.5(6 \mathrm{H}$, compl. abs.).

1-Cyclohexylthiomethyl-2,2-dibromocyclopropane (3d), b.p. $100-102^{\circ} \mathrm{C} \quad(0.01 \mathrm{mmHg})$. Anal. $\mathrm{C}_{10} \mathrm{H}_{14} \mathrm{Br}_{2} \mathrm{~S}: \mathrm{C}, \mathrm{H}$. ${ }^{1} \mathrm{H}$ NMR $\left(\mathrm{CCl}_{4}\right): \delta$ 1.0-2.1 (14H, compl. abs.) $2.65(2 \mathrm{H}, \mathrm{m})$.

Reactions of sulfides 3 with methyllithium. To a stirred solution of the sulfide $3(5 \mathrm{mmol})$ in $25 \mathrm{ml}$ of dry ether, kept at $-78^{\circ} \mathrm{C}\left(\right.$ method A) or $0^{\circ} \mathrm{C}$ (method B), an ethereal solution of methyllithium $(6 \mathrm{mmol})$ was added dropwise. The reaction mixture was stirred at the same temperature for $1 \mathrm{~h}$. Water was added and the ether phase separated, washed with brine and dried $\left(\mathrm{MgSO}_{4}\right)$. The ether was evaporated and the volatile product collected by distillation under reduced pressure. The residue was purified by column chromatography (neutral $\mathrm{Al}_{2} \mathrm{O}_{3}$, ether-pentane). The components of the volatile product was separated by preparative GLC. (SE 30, Apiezone L, or OV 17, $3 \mathrm{~m}$ ).

4-Phenylthio-1,2-butadiene (5a), b.p. $47-48^{\circ} \mathrm{C}$ (0.015 mmHg); IR (film) $1960,855 \mathrm{~cm}^{-1} ;{ }^{1} \mathrm{H}$ NMR $\left(\mathrm{CCl}_{4}\right) \delta 3.51(2 \mathrm{H}, \mathrm{td}, J=2.5 \mathrm{~Hz}, 7.5 \mathrm{~Hz}) 4.68(2 \mathrm{H}, \mathrm{m})$ $5.20(1 \mathrm{H}, \mathrm{m}) 7.27(5 \mathrm{H}, \mathrm{m}) ;{ }^{13} \mathrm{C} \mathrm{NMR}\left(\mathrm{CDCl}_{3}\right) \delta 33.4$ $\left(\mathrm{CH}_{2}\right) 76.1(=\mathrm{C}) 87.5(=\mathrm{C}) 126.3,128.8,130.2$, $135.8(\mathrm{Ph}) 209.6(\mathrm{C})$.

trans-2,3'-Bis (phenylthiomethyl) -1,1'-bicyclopropylidene $(10 \mathrm{a})$, m.p. $106-107^{\circ} \mathrm{C}$ (from $\mathrm{CCl}_{4}$ ); ${ }^{1} \mathrm{H}$ $\operatorname{NMR}\left(\mathrm{CDCl}_{3}\right) \delta 1.1(1 \mathrm{H}, \mathrm{m}) 1.38(1 \mathrm{H}, \mathrm{m}) 1.8(1 \mathrm{H}, \mathrm{m})$ $2.95(2 \mathrm{H}, \mathrm{m}) 7.25(5 \mathrm{H}, \mathrm{m}) ;{ }^{13} \mathrm{C}$ NMR, see Table 2. The configuration has been determined by $\mathrm{X}$-ray diffraction. ${ }^{13}$

4-Benzylthio-1,2-butadiene (5b), IR (film) 1960 , $855 \mathrm{~cm}^{-1} ;{ }^{1} \mathrm{H}$ NMR $\left(\mathrm{CCl}_{4}\right) \delta 2.93(2 \mathrm{H}, \mathrm{m}) 3.63(2 \mathrm{H}$, s) $4.73(2 \mathrm{H}, \mathrm{m}) 5.0(1 \mathrm{H}, \mathrm{m}) 7.17(5 \mathrm{H}, \mathrm{m})$; $\mathrm{MS}: \mathrm{m} / e$ $176\left(\mathrm{M}^{+}\right)$.

2-Phenyl-3-thiabicyclo 3.1.0 hexane (6) was formed as a stereoisomeric mixture.

endo-6 (72\%), ${ }^{1} \mathrm{H}$ NMR $\left(\mathrm{CCl}_{4}\right) \delta 0.3-1.9(4 \mathrm{H}$, several m) $3.07(2 \mathrm{H}, \mathrm{m}) 4.68(1 \mathrm{H}, \mathrm{d}, J=3 \mathrm{~Hz}) 7.17$ $(5 \mathrm{H}, \mathrm{m}){ }^{13} \mathrm{C} \mathrm{NMR}\left(\mathrm{CCl}_{4}\right) \delta 2.9$ (cyclopropyl $\mathrm{CH}_{2}$ ) 18.824 .8 (Cyclopropyl $\mathrm{CH}) 35.2\left(\mathrm{CH}_{2}-\mathrm{S}\right) 52.5$ $(\mathrm{CH}-\mathrm{S})$ 126.3, 126.9, 127.5, $128.0(\mathrm{Ph}) ; \mathrm{MS}: \mathrm{m} / \mathrm{e}$ $176\left(\mathrm{M}^{+}\right)$.

exo-6, $(28 \%):{ }^{1} \mathrm{H}$ NMR $\left(\mathrm{CCl}_{4}\right) \delta 0.3-1.9(4 \mathrm{H}$, several m) $3.07(2 \mathrm{H}, \mathrm{m}) 4.31(1 \mathrm{H}, \mathrm{s}) 7.17(5 \mathrm{H}, \mathrm{m}$; ${ }^{13} \mathrm{C}$ NMR $\left(\mathrm{CCl}_{4}\right) \delta 5.6$ (Cycloprop. $\left.\mathrm{CH}_{2}\right)$ 21.1, 26.5 (Cyclopropyl CH) $33.7\left(\mathrm{CH}_{2}-\mathrm{S}\right) 53.4(\mathrm{CH}-\mathrm{S})$ 126.3, 126.9, 127.5, 128.0 (Ph); MS: $m / e 176\left(\mathrm{M}^{+}\right)$.

2 - Bromo-2 - methyl-1 - benzylthiomethylcyclopropane $(9 b),{ }^{1} \mathrm{H} \mathrm{NMR}\left(\mathrm{CCl}_{4}\right) \delta 0.80(3 \mathrm{H}, \mathrm{m}) 1.70(3 \mathrm{H}$, s) $4.26(2 \mathrm{H}, \mathrm{m}) 3.70(2 \mathrm{H}, \mathrm{s}) 7.21(5 \mathrm{H}, \mathrm{s})$; $\mathrm{MS}: \mathrm{m} / \mathrm{e}$ 272, $270\left(\mathrm{M}^{+}\right)$.

2,3'-Bis( benzylthiomethyl)-1,1'-bicyclopropylidene (10b), ${ }^{1} \mathrm{H}$ NMR $\left(\mathrm{CCl}_{4}\right) \delta 0.7-1.4(6 \mathrm{H}$, compl. abs.) $2.0-2.6(4 \mathrm{H}, \mathrm{m}) 3.63\left(4 \mathrm{H}\right.$, br.s. $7.11(10 \mathrm{H}, \mathrm{s}) ;{ }^{13} \mathrm{C}$
NMR, see Table 2.

4-Isopropylthio-1,2-butadiene (5c). IR (film) 1950, $840 \mathrm{~cm}^{-1} ;{ }^{1} \mathrm{H} \mathrm{NMR}\left(\mathrm{CCl}_{4}\right) \delta 1.23(6 \mathrm{H}, \mathrm{d}, J=6.5 \mathrm{~Hz})$ $\sim 3$ and $3.08(3 \mathrm{H}, \mathrm{m}$ and $\mathrm{dt}) 4.7(2 \mathrm{H}, \mathrm{m}) 5.03(1 \mathrm{H}, \mathrm{m})$ : MS: $m / e 128\left(\mathrm{M}^{+}\right)$.

2,2-Dimethyl-3-thiabicyclo 3.1.0 hexane (7). ${ }^{1} \mathrm{H}$ $\operatorname{NMR}\left(\mathrm{CCl}_{4}\right): \delta 0.3(1 \mathrm{H}, \mathrm{m}) 0.7-1.5(3 \mathrm{H}$, compl.abs. $)$ $1.32(3 \mathrm{H}, \mathrm{s}) 1.40(3 \mathrm{H}, \mathrm{s}) 2.93\left(2 \mathrm{H}, \mathrm{ABX}, J_{\mathrm{AB}}=11 \mathrm{~Hz}\right.$, $J_{\mathrm{AX}}=3 \mathrm{~Hz}$ ). ${ }^{13} \mathrm{C} \mathrm{NMR}\left(\mathrm{CCl}_{4}\right) \delta 3.8$ (cyclopropyl $\mathrm{CH}_{2}$ ) 19.7, 26.1 (cyclopropyl $\mathrm{CH}$ ) 31.3, $32.2\left(\mathrm{CH}_{3}\right)$ $33.7\left(\mathrm{CH}_{2}-\mathrm{S}\right), 53.4(\mathrm{C}-\mathrm{S})$; MS: m/e $128\left(\mathrm{M}^{+}\right)$.

2-Bromo-1-isopropylthiomethyl-2-methylcyclopropane (9c). Mixture of stereoisomers by GLC (SP $\left.2100,3 \mathrm{~m}, 140^{\circ} \mathrm{C}\right){ }^{1} \mathrm{H}$ NMR $\left(\mathrm{CCl}_{4}\right) \delta 0.92(3 \mathrm{H}, \mathrm{m})$ $1.27(6 \mathrm{H}, \mathrm{d}, J=6.5 \mathrm{~Hz}) 1.77(4 \mathrm{H}, \mathrm{s}) 2.5-3.2(3 \mathrm{H}$, compl.abs.); MS: m/e 224, $222\left(\mathrm{M}^{+}\right)$.

$2,3^{\prime}$ - Bis (isopropylthiomethyl)-1,1'-bicyclopropylidene (10c). ${ }^{1} \mathrm{H}$ NMR $\left(\mathrm{CCl}_{4}\right) \delta 0.6-1.6(3 \mathrm{H}$, compl.abs.) $1.25(6 \mathrm{H}, \mathrm{d}) 2.57(2 \mathrm{H}$, br.d.) $2.97(1 \mathrm{H}, \mathrm{m})$; ${ }^{13} \mathrm{C}$ NMR, see Table 2.

4-Cyclohexylthio-1,2-butadiene (5d). IR (film) $1955,845 \mathrm{~cm}^{-1} ;{ }^{1} \mathrm{H}$ NMR $\left(\mathrm{CCl}_{4}\right) \delta 1.1-2.1(10 \mathrm{H}$, compl. abs.) $2.65(1 \mathrm{H}, \mathrm{m}) 3.08(2 \mathrm{H}, \mathrm{dt}, J=8 \mathrm{~Hz}$, $2.5 \mathrm{~Hz}) 4.5-5.3$ (3H, compl.abs.).

3,4-Methano-1-thiaspiro[5.6]decane (8). ${ }^{1} \mathrm{H}$ NMR $\left(\mathrm{CCl}_{4}\right) \delta 0.30(1 \mathrm{H}, \mathrm{m}), 0.87(1 \mathrm{H}, \mathrm{m}), 1.0-2.0$ (12H, compl.abs.), $4.53\left(2 \mathrm{H}, \mathrm{ABX} J_{\mathrm{AB}}=11 \mathrm{~Hz}\right.$, $\left.J_{\mathrm{AX}}=4 \mathrm{~Hz}\right) \cdot{ }^{13} \mathrm{C}$ NMR $\left(\mathrm{CCl}_{4}\right) \delta 3.1$ (cyclopropyl $\mathrm{CH}_{2}$ ) 19,3, 23.2 (cyclopropyl $\mathrm{CH}$ ) 25.7, 29.9, 32.6 (cyclohexyl $\left.\mathrm{CH}_{2}\right) 36.6\left(\mathrm{~S}-\mathrm{CH}_{2}\right) 39.6(\mathrm{~S}-\mathrm{C})$; MS: $m / e 168\left(\mathrm{M}^{+}\right)$.

2-Bromo-1-cyclohexylthiomethyl-2-methylcyclopropane (9d). ${ }^{1} \mathrm{H}$ NMR $\left(\mathrm{CCl}_{4}\right) \delta 1.75(3 \mathrm{H}, \mathrm{s}) 1.4-$ $2.1(13 \mathrm{H}$, compl.abs.) $2.6(3 \mathrm{H}, \mathrm{m})$.

2,3'-Bis(cyclohexylthiomethyl)-1,1'-bicyclopropylidene (10d). ${ }^{1} \mathrm{H}$ NMR $\left(\mathrm{CCl}_{4}\right) \delta 0.7-2.2(13 \mathrm{H}$, compl.abs.) $2.2-3.1$ (3H, compl.abs.); ${ }^{13} \mathrm{C}$ NMR see Table 2.

\section{REFERENCES}

1. Kirmse, W. Carbene Chemistry, Academic, New York 1971; Jones, W. M. and Brinker, V. H. In Marchand, A. P. and Lehr, R. E., Eds., Pericyclic Reactions, Academic, New York 1977, Chapter 3; Hopf, H. In Patai, S., Ed., The Chemistry of Ketenes, Allenes and Related Compounds, Part 2 , Wiley, New York 1980, Chapter 20; Jones, W. M. In de Mayo, P., Ed., Rearrangements in Ground and Excited States, Academic, New York 1980, Chapter 3.

2. a. Moore, W. R., Ward, H. R. and Merritt, R. F. J. Am. Chem. Soc. 83 (1961) 2019; b. Moore, W. R. and Ward, H. R. J. Org. Chem. 25 (1960) 2073.

3. Baird, M. S. Chem. Commun. (1971) 1145.

4. Paquette, L. A., Zon, G. and Taylor, R. T. J. Org. Chem. 39 (1974) 2677. 
5. Nilsen, N. O., Sydnes, L. K. and Skattebøl, L. Chem. Commun. (1978) 128; Acta Chem. Scand. B 36 (1982) 587.

6. Baird, M. S. and Kaura, A. C. Chem. Commun. (1976) 356; Boswell, R. F. and Bass, R. G. J. Org. Chem. 40 (1975) 2419.

7. Baird, M. S. J. Chem. Res. (S) (1981) 352.

8. Labeish, N. N., Kharicheva, E. M., Mandel'shtam, T. V. and Kostikov, R. R. Zh. Org. Khim. 14 (1978) 878.

9. Parham, W. E. and Groen, S. H. J. Org. Chem. 29 (1964) 2214; 30 (1965) 728; 31 (1966) 1694.

10. Malloy, T. B., Jr. J. Mol. Spectrosc. 49 (1974) 432.

11. Wendisch, D. and Naegele, W. Org. Magn. Reson. 2 (1970) 619.

12. Kitatani, K., Hiyama, T. and Nozaki, H. Bull. Chem. Soc. Jpn. 50 (1977) 3288.

13. Rømming, C. Acta Chem. Scand. A 35 (1981) 725.

14. Warner, P., Chang, S.-C., Powell, D. R. and Jacobson, R. A. Tetrahedron Lett. 22 (1981) 533.

15. Lord, R. C. and Wurrey, C. J. Spectrochim. Acta A 30 (1974) 915.

16. Klæboe, P., Larsen, H. and Skattebøl, L. Acta Chem. Scand. B. To be published.

17. Seebach, D., Siegel, H., Gabriel, J. and Hässig, R. Helv. Chim. Acta 63 (1980) 2046 and references therein.

18. Skattebøl, L. Tetrahedron Lett. (1970) 2361; Moore, W. R., Taylor, K. G., Müller, P., Hall, S. S. and Gaibel, Z. L. F. Ibid. (1970) 2365; Moore, W. R. and Hill, J. B. Ibid. (1970) 4343, 4553; Reinharz, R. B. and Fonken, G. J. Ibid. (1974) 441; Hamon, D. P. G. and Trenerry, V. C. Ibid. (1974) 1371; Shono, T., Nishiguchi, I., Komamura, T. and Fujita, K. Ibid. (1977) 4327; Hamon, D. P. G. and Trenerry, V. C. Aust. J. Chem. 33 (1980) 809.

19. Brown, D. W., Hendrick, M. E. and Jones, M., Jr. Tetrahedron Lett. (1973) 3951.

20. Baird, M. S. Chem. Commun. (1979) 776.

21. Doering, W. von E., Knox, L. H. and Jones, M., Jr. Org. Chem. 24 (1959) 136.; Seyferth, D., Mai, V. A. and Gordon, M. E., J. Org. Chem. 35 (1970) 1993; Seyferth, D. and Cheng, Y. M., J. Am. Chem. Soc. 95 (1973) 6763.

22. Dodson, R. C., Hayes, D. M. and Hoffmann, R. J. Am. Chem. Soc. 93 (1971) 6188; Hill, E. A. J. Org. Chem. 37 (1972) 4008.

23. Lepley, A. R. and Giumanini, A. G. In Thyagarajan, B. S., Ed., Mechanisms of Molecular Migrations, Wiley-Interscience, New York 1971, Vol. 3, p. 297.

24. Ando, W., Nakayama, K., Ichibori, K. and Migita, T. J. Am. Chem. Soc. 91 (1969) 5164.

25. Iwamura, H., Imahashi, Y. and Kushida, K. Tetrahedron Lett. (1975) 1401.
26. Kirmse, W. and Buschhoff, M. Chem. Ber. 102 (1969) 1087; Hata, Y. and Watanabe, M. Tetrahedron Lett. (1972) 4659.

27. Loozen, H. J. J., Castenmiller, W. A., Buter, E. J. M. and Buck, H. M. J. Org. Chem. 41 (1976) 2965.

28. Moore, W. R. and Bach, R. D. J. Am. Chem. Soc. 94 (1972) 3148.

29. Taylor, K. G., Chancy, J. and Deck, J. C. J. Am. Chem. Soc. 98 (1976) 4163.

Received February 8, 1982. 